\title{
Transcervical minimally invasive esophagectomy: hemodynamic study on an animal model
}

\author{
Xiaosang Chen ${ }^{1 \#}$, Shuanggen Xue ${ }^{2 \#}$, Jun Xü ${ }^{3 \#}$, Ming Zhong ${ }^{4}$, Xiaochuan Liu ${ }^{5}$, Guangyi Lin ${ }^{6}$, Yaxing Shen ${ }^{1,7}$, \\ Lijie Tan ${ }^{1}$
}

${ }^{1}$ Department of Thoracic Surgery, Zhongshan Hospital, Fudan University, Shanghai, China; ${ }^{2}$ Jiangyan Hospital of Traditional Chinese Medicine Affiliated to Nanjing University of Traditional Chinese Medicine, Nanjing, China; ${ }^{3}$ Qingpu Branch of Zhongshan Hospital, Affiliated to Fudan University, Shanghai, China; ${ }^{4}$ Department of Critical Care Medicine, Zhongshan Hospital, Fudan University, Shanghai, China; ${ }^{5}$ Department of Thoracic Surgery, Guang-an People's Hospital, Sichuan, China; ${ }^{6}$ Shanghai Medical College, Fudan University, Shanghai, China; ${ }^{7}$ Department of Thoracic Surgery, National Cancer Center/National Clinical Research Center for Cancer/Cancer Hospital, Chinese Academy of Medical Sciences and Peking Union Medical College, Beijing, China

Contributions: (I) Conception and design: X Chen, Y Shen; (II) Administrative support: Y Shen, X Liu; (III) Provision of study materials or patients: M Zhong, L Tan; (IV) Collection and assembly of data: S Xue, J Xu; (V) Data analysis and interpretation: X Chen, G Lin, Y Shen; (VI) Manuscript writing: All authors; (VII) Final approval of manuscript: All authors.

"These authors contributed equally to this work.

Correspondence to: Yaxing Shen, MD. Department of Thoracic Surgery, Zhongshan Hospital, Fudan University, Shanghai, China; Email: shen.yaxing@zs-hospital.sh.cn; Lijie Tan, MD, FACS. Department of Thoracic Surgery, Zhongshan Hospital, Fudan University, 180 Fenglin Road, Shanghai, China. Email: tan.lijie@zs-hospital.sh.cn.

Background: Transcervical esophagectomy is a less invasive procedure performed within mediastinum. However, the mediastinum offers limited surgical space and the surgery via this route differs from conventional minimally invasive esophagectomy. Therefore, the physiological study of this surgical approach on an animal model would be necessary before the procedure gained more popularity.

Methods: We conducted transcervical minimally invasive esophagectomy on animal model (swine) under $\mathrm{CO}_{2}$ pneumomediastinum. The hemodynamic parameters were monitored using float catheter cannulated via right jugular vein. At different anatomical level (the upper, middle, and lower thoracic part of the animal esophagus), increased artificial pneumomediastinal pressures $(0,4,8,12$, and $16 \mathrm{mmHg}$ ) were consecutively allocated to record the intra-operative changes of blood pressure, cardiac output (CO), central venous pressure (CVP), pulmonary artery pressure (PAP) and extravascular lung water (EVLW). Meanwhile, the surgical field under different pneumomediastinum pressure was recorded and balanced with animals' hemodynamic changes to determine the optimal pressure for transcervical minimally invasive esophagectomy.

Results: The animal procedures were accomplished without conversions. During the upper thoracic stage, increased $\mathrm{CO}_{2}$ pressures did not lead to significant changes in hemodynamic parameters including the blood pressure, CO, CVP, PAP or the level of EVLW. During the middle thoracic stage, pneumomediastinum under 4-12 mmHg did not lead to significant changes in hemodynamic parameters. However, pneumomediastinum at $16 \mathrm{mmHg}$ resulted in lower $\mathrm{CO}(\mathrm{P}=0.038)$ when compared to $0-12 \mathrm{mmHg}$. During lower thoracic stage, as the pneumomediastinum pressures increased from 0 to $16 \mathrm{mmHg}$, significant decrease in $\mathrm{CO}(\mathrm{P}=0.022)$, and increase in $\mathrm{CVP}(\mathrm{P}=0.036)$ was recorded. In compared to $4 \mathrm{mmHg}$ pneumomediastinum, the surgical field under $8-16 \mathrm{mmHg}$ artificial $\mathrm{CO}_{2}$ pneumomediastinum was suitable for mediastinal manipulation.

Conclusions: During transcervical minimally invasive esophagectomy on animal model, the mobilization of swine thoracic esophagus with optimal pneumomediastinum pressure $8-12 \mathrm{mmHg}$ is safe and effective based on hemodynamic analysis. 
Keywords: Transcervical minimally invasive esophagectomy; pneumomediastinum; Transcervical minimally invasive esophagectomy; pneumomediastinum; hemodynamic study

Submitted May 11, 2020. Accepted for publication Oct 10, 2020.

doi: $10.21037 /$ jtd-20-1905

View this article at: http://dx.doi.org/10.21037/jtd-20-1905

\section{Introduction}

Historically, transhiatal esophagectomy (THE) marked the beginning of transcervical resection to the esophageal lesions (1). Under complete "blind" conditions, the surgeon's hands were used to mobilize the esophagus (2-4). However, from the surgical perspective, there is a risk of injury towards the mediastinal structure during the blunt mobilization $(1,5)$. Meanwhile, from the oncological perspective, the procedure also defects in mediastinal lymph node dissection, resulting in undefined $\mathrm{N}$ stage post-operatively (1). By means of mediastinoscopy assisted esophagectomy (MAE), the exposure and visualization of mediastinum could be achieved, which surpassed the "blind and blunt" THE in the surgical resection of esophageal cancer $(3,6)$. Due to the space limitation of the mediastinum, only one instrument could be implemented into the operating field during MAE, and it is also technically challenging to perform anatomical mediastinal lymph node dissection using MAE.

To overcome this limitation, artificial $\mathrm{CO}_{2}$ pneumomediastinum was established to expand the surgical field via an air-proof wound protector in cervical incision (7). The surgical instruments, in together with the endoscopic system also could be implemented to complete esophagectomy via the wound protector. The placement of multiple surgical instruments conforms to the surgeon's two-handed operation habit and the expanded surgical field further guarantees the operator's hand-eye coordination, making esophagectomy and systemic lymph node dissection possible (8). Parker et al. made first successful attempt on animal, and thereafter reported the application of this technique in eight patients $(9,10)$. Tokairin et al. conducted an in-depth exploration of the procedure and achieved a complete systemic lymphadenectomy from the mediastinum (11). Wang and colleagues, also carried out exploration attempts on the procedure, and achieved similar clinical results (12). More recently, Chiu et al. completed transcervical esophagectomy using a novel single-port robotic surgical system on cadaver, which demonstrates that transcervical esophagectomy is technically feasible and can be completed with the novel da Vinci SP Surgical System (13).

Yet, the physiological effect of pneumomediastinum remain less studied in transcervical minimally invasive esophagectomy. On the other hand, the optimal pressure of artificial pneumomediastinum will also contributes to minimize the morbidities from this traumatic procedure.

We present the following article in accordance with the ARRIVE reporting checklist (available at http://dx.doi. org/10.21037/jtd-20-1905).

\section{Objectives}

At different anatomical planes, to analyze the hemodynamic changes during transcervical minimally invasive esophagectomy under artificial pneumomediastinum on an animal model.

\section{Methods}

\section{Experimental animals and surgical procedures}

Experiments were performed under a project license (No. 2009156) granted by ethics board of Zhongshan Hospital, in compliance with institutional guidelines for the care and use of animals. The experimental animals used were Bama miniature swine (two male and four female) of 2-3-monthold, weighing $25-32 \mathrm{~kg}$. They were housed in groups of three on straw bedding in pens with solid concrete floors. Room temperature was controlled at $24 \pm 2{ }^{\circ} \mathrm{C}$. All animals were fed twice daily, and water was provided ad libitum. Animals with disease or unexplained weight loss were excluded from this study. A total of six experimental animals underwent simulated transcervical minimally invasive esophagectomy.

The experimental animal was placed in the supine position. The surgeon and the assistant were located on the cranial side of the experimental animal. The highdefinition display was placed on the caudal side of the experimental animal (Figure 1). On the experimental animal (swine), the anterior margin of the left sternocleidomastoid 


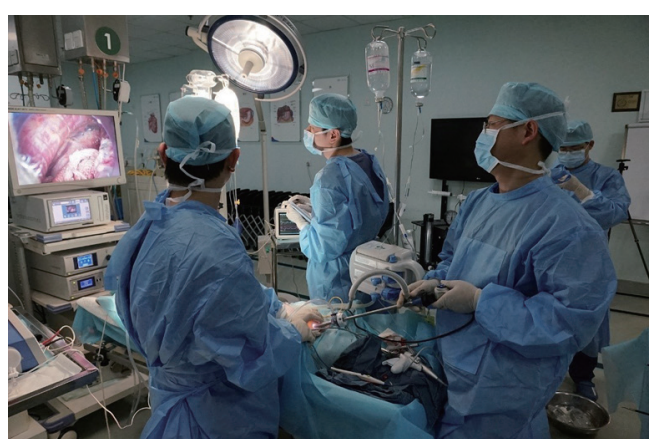

Figure 1 Personnel arrangement during the operation.

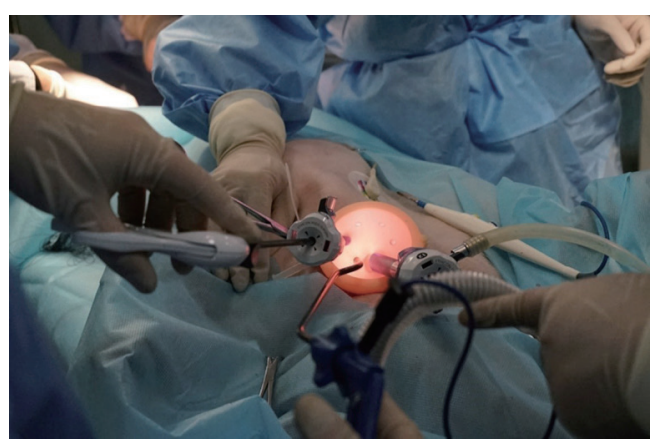

Figure 2 Wound protector and the instrumental set on the cervical incision. During the experiment, the air-proof wound protector was placed via the cervical incision, $\mathrm{CO}_{2}$ were introduced via the $12 \mathrm{~mm}$ trocar to establish artificial pneumomediastinum.

muscle was marked as the incision. The cervical esophagus was mobilized to the thoracic inlet. An air-proof wound protector was inserted and $\mathrm{CO}_{2}$ was inflated into the mediastinum. The artificial pneumothorax machine was connected to the protector to maintain the pressure during the procedure. Three trocars (two trocars were $5 \mathrm{~mm}$ and one trocar was $12 \mathrm{~mm}$ in diameter) were implemented towards the wound protector. Two endoscopic instruments were inserted through the two trocars $(5 \mathrm{~mm})$ and the endoscope (Karl Storz, Tuttlingen, Germany) was introduced through the $12 \mathrm{~mm}$ trocar (shown in Figure 2).

Simulated surgery on animal model: esophagus under artificial pneumo-mediastinum was mobilized via the cervical single port. The anatomic landmark was shown consecutively, as per the reference from three-dimensional anatomical atlas (BioDigital, New York, NY, USA). The trachea, left main bronchus (LMB), singular vein, recurrent laryngeal nerve and pulmonary vein were shown in order during the operation, and recorded under the endoscope.
The effects of artificial carbon dioxide pneumomediastinum on experimental animal hemodynamics was evaluated: before starting the esophageal mobilization, the right transvenous catheter, Swan-Ganz pulmonary artery catheter (Edward, Irvine, CA, USA), in together with a PiCCO catheter (Pulsion, Feldkirchen, Germany) were placed to monitor the intraoperative respiration, circulation, and tissue perfusion of the experimental animal.

In different anatomical planes, the effect of $\mathrm{CO}_{2}$ pneumomediastinum on experimental animals was evaluated: under baseline $(0 \mathrm{mmHg}), 4,8,12,16 \mathrm{mmHg}$ artificial $\mathrm{CO}_{2}$ pneumomediastinum conditions, each pressure was maintained 5 minutes during the experiment. The vital signs and hemodynamic parameters including central venous pressure (CVP), pulmonary artery pressure (PAP), and extravascular lung water (EVLW) were recorded. Intraoperatively, the images of the surgical field of the three anatomic planes were recorded at different levels of artificial pneumomediastinal pressure.

\section{Statistical analysis}

Experimental data were analyzed using SPSS 17.0 statistical software. The diameters were expressed as mean \pm standard deviation (SD). Wilcoxon's rank-sum test was used for the analysis of group differences. The $\mathrm{P}$ value less than 0.05 was considered statistically significant.

\section{Results}

All six animals underwent simulated transcervical minimally invasive esophagectomy were subjected to hemodynamic monitoring, while one of them failed in data collection due to the dislocation of the catheter during the surgery. The remaining five completed data recording under $0-16 \mathrm{mmHg}$ pneumomediastinal pressure.

The surgery included the transcervical mobilization of the upper, middle and lower thoracic esophagus, the laparoscopic mobilization of the gastric conduit and the anastomosis in the cervical incision. After laparoscopic mobilization of the gastric conduit, the conduit was anastomosed to the stump of the cervical esophagus of the experimental animal. The operation procedure concluded after the anastomosis in the cervical incision (Figure 3).

The major adverse events were the injury to the organs surround the esophagus during the operation. To prevent the damage, we adjusted the pressure of pneumomediastinum to make it suitable for the operation. 


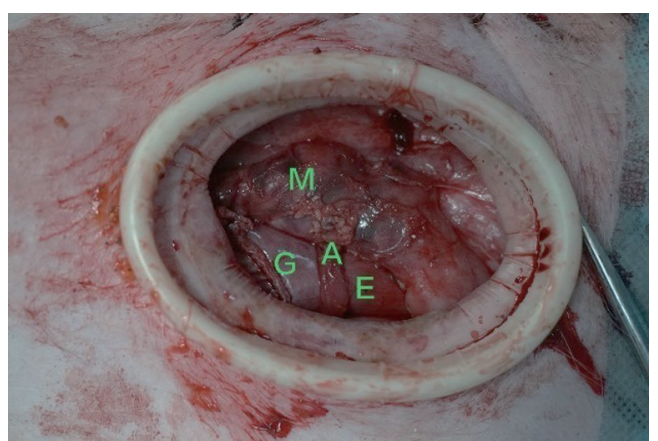

Figure 3 Gastric esophageal anastomosis on animal model. $\mathrm{G}$, gastric conduit; E, proximal esophagus; A, anastomosis; $\mathrm{M}$, sternocleidomastoid muscle.
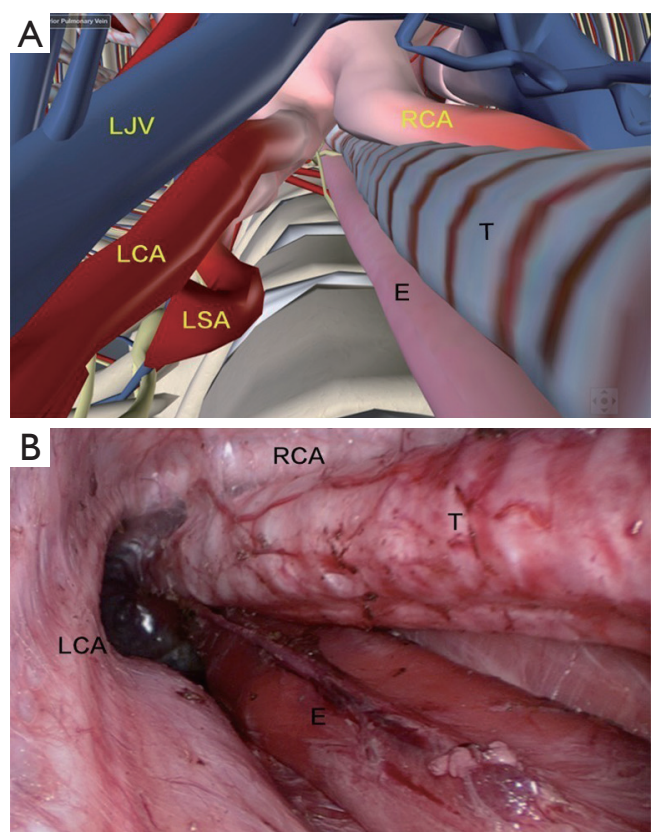

Figure 4 Illustration of the cervical esophagus mobilized to the thoracic inlet. The digital (A) and endoscopic anatomy (B) of the surgical field of cervical esophagus during transcervical minimally invasive esophagectomy. T, trachea; E, esophagus; LCA, left common carotid artery; RCA, right brachial artery; LJV, left internal jugular vein; LSA, left subclavian artery.

Also, we used curved surgical instruments to avoid the instrumental collisions during the surgery.

\section{Hemodynamic analysis at upper thoracic esophagus}

In the upper thoracic procedure, the esophagus is marked by the surrounding mediastinal structures: the esophagus is located on the left side of the trachea, and the inferior thyroid pole, the carotid sheath, and the left recurrent laryngeal nerve (LRN) along the esophagus. The anterior border consisted of left subclavian artery (LSA) and partly the lateral border of the trachea. The posterior border is the anterior fascia of the vertebral body, and the lateral boundary is the left common carotid artery (LCA) originates from the aortic arch. The anatomical mark in the surgery, in together with the digital anatomy is shown in Figure 4.

The mean values of hemodynamic parameters including the arterial blood pressure (ABP), CVP, cardiac output (CO), PAP and EVLW of the experimental animals during the upper thoracic procedure are shown in Table 1: the experimental animals were subjected to $4-16 \mathrm{mmHg}$ carbon dioxide artificial pressure, and the hemodynamic parameters did not change significantly.

\section{Hemodynamic analysis at middle thoracic esophagus}

The anatomy of the middle thoracic esophagus: the middle thoracic esophagus ranges from the thoracic outlet to the level of 4th thoracic vertebrae (trachea bifurcation). The esophagus deviates to the right while running caudally. The anterior border of the esophagus is the tracheal membrane, and the posterior border is the vertebral body, the lateral side is attached to the left mediastinal pleura, and the aortic arch (from the aortic arch upward to the LCA) is visible during the mobilization. The medial side is attached to the right mediastinal pleura (shown in Figure 5).

During the middle thoracic surgery, the experimental animals were able to receive 4-16 $\mathrm{mmHg}$ pneumomediastinal pressure, while carbon dioxide artificial pneumomediastinum under $16 \mathrm{mmHg}$ resulted in significantly lower $\mathrm{CO}(\mathrm{P}=0.038)$ in compared to 4-12 $\mathrm{mmHg}$ (shown in Table 2).

\section{Hemodynamic analysis at lower thoracic esophagus}

The anatomy of the lower thoracic esophagus: the lower thoracic part is mainly below the level of the carina, located above the eighth thoracic plane. The posterior border of the esophagus in this stage is the vertebrae body, and the bilateral boundary is the left and right visceral pleura. The anterior border is the left atrium. The digital and the endoscopic anatomy of the lower thoracic region are shown in Figure 6.

During the lower thoracic stage, the experimental 
Table 1 Relationship between $\mathrm{CO}_{2}$ pressure and hemodynamic parameters during upper thoracic stage

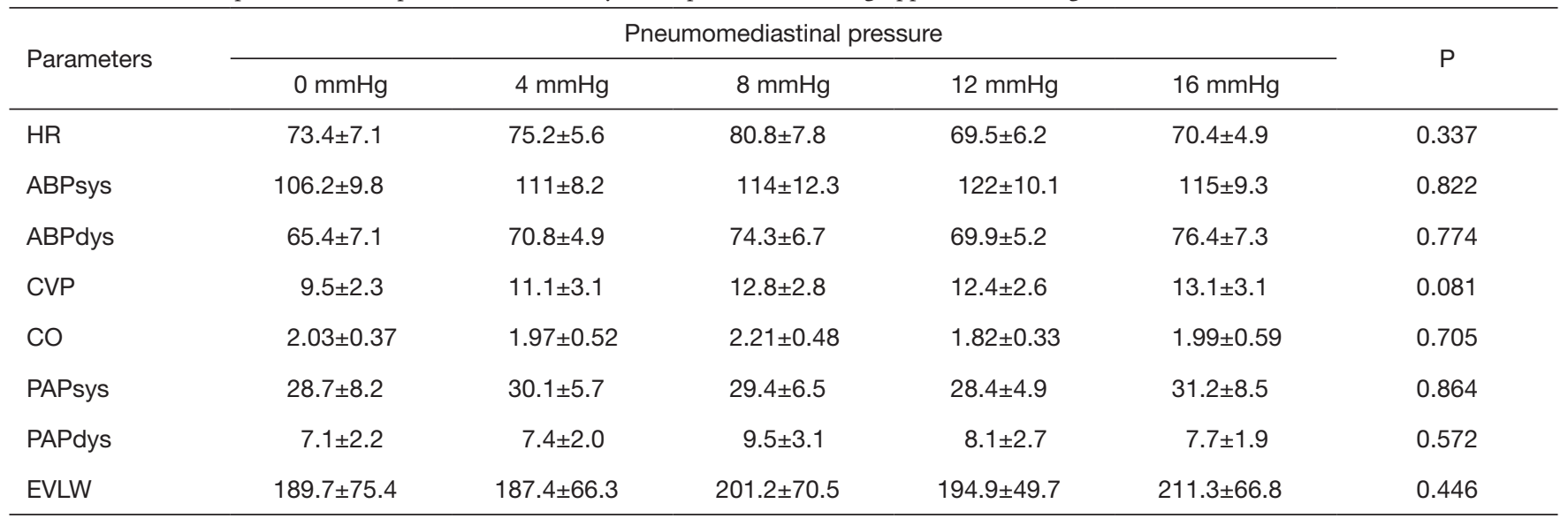

Results expressed as mean \pm SD. SD, standard deviation; HR, heart rate (bpm); ABPsys, systolic arterial blood pressure (mmHg); ABPdys, diastolic arterial blood pressure $(\mathrm{mmHg})$; CVP, central venous pressure $\left(\mathrm{cmH}_{2} \mathrm{O}\right)$; $\mathrm{CO}$, cardiac output $(\mathrm{L} / \mathrm{min})$; PAPsys, systolic pulmonary artery pressure $(\mathrm{mmHg})$; PAPdys, diastolic pulmonary artery pressure $(\mathrm{mmHg})$; EVLW, extravascular lung water $(\mathrm{mL} / \mathrm{kg})$.
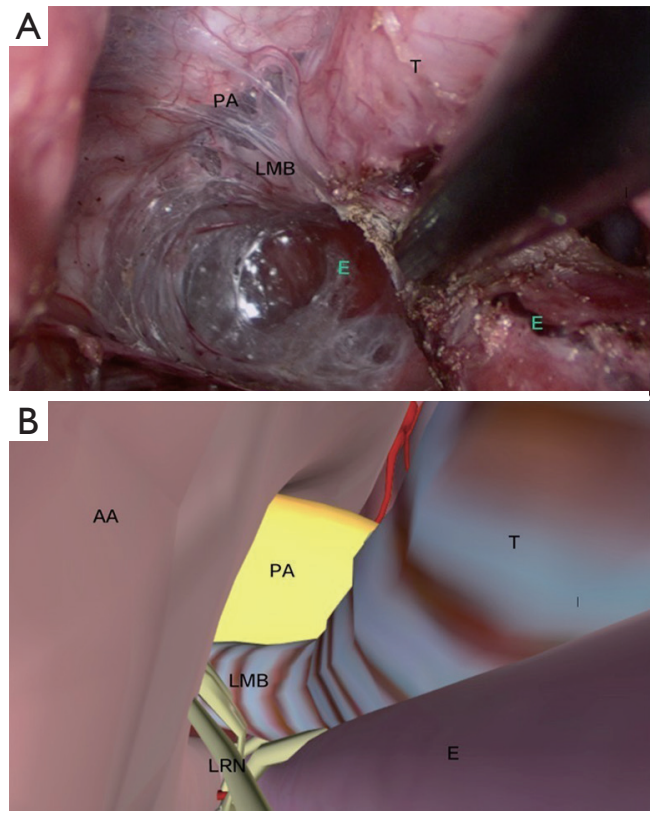

Figure 5 The digital (A) and endoscopic anatomy (B) of the surgical field of the left side of middle thoracic esophagus during transcervical minimally invasive esophagectomy. T, trachea; E, esophagus; LMB, left main bronchus; AA, aortic arch; PA, pulmonary artery; LRN, left recurrent laryngeal nerve.

animals could receive artificial pneumomediastinum under the pressure between 4-16 mmHg. As pneumomediastinal pressure increased from 4 to $16 \mathrm{mmHg}$, the experimental swine showed significant decrease in $\mathrm{CO}(\mathrm{P}=0.022)$ and increase in CVP $(\mathrm{P}=0.036)$. The hemodynamic parameters were shown in Table 3.

The surgical fields of transcervical minimally invasive esophagectomy under the pressure of $4-16 \mathrm{mmHg}$ pneumomediastinum were recorded: the pressure above $8 \mathrm{mmHg}$ was suitable for operation (shown in Figure 7).

\section{Discussion}

The study introduced artificial pneumomediastinum to experimental swine and analyzed the hemodynamic changes under at different anatomical levels. Our finding suggested that: as the anatomical plane deepens, the maximal pneumomediastinal pressure would be decreased to keep the balance between the hemodynamic stability and visibility of the surgical field.

This animal study was carried out under following conditions: firstly, the clinical experience of esophageal mobilization under mediastinoscopy, showing identical oncological results in compared to thoracoscopic esophagectomy in our retrospective study (14). Secondly, the technical advances on minimally invasive esophagectomy, including the accumulation of surgical experience and the application of artificial pneumothorax, which facilitated esophageal mobilization and provide a reference for the introduction of artificial pneumomediastinum in this study (15). Thirdly, the clinical application of uniportal minimally invasive surgery, which makes the tunnel view more familiar for the surgeons under thoracoscope (16). The above factors 
Table 2 Relationship between $\mathrm{CO}_{2}$ pressure and hemodynamic parameters during middle thoracic stage

\begin{tabular}{|c|c|c|c|c|c|c|}
\hline Parameters & \multicolumn{5}{|c|}{ Pneumomediastinal pressure } & $\mathrm{P}$ \\
\hline $\mathrm{HR}$ & $70.3 \pm 5.6$ & $74.7 \pm 4.5$ & $70.4 \pm 7.7$ & $70.9 \pm 6.2$ & $73.2 \pm 5.2$ & 0.832 \\
\hline ABPsys & $100.5 \pm 9.2$ & $109.0 \pm 8.1$ & $116.1 \pm 13.1$ & $114.4 \pm 9.2$ & $113.7 \pm 12.4$ & 0.887 \\
\hline ABPdys & $57.7 \pm 7.1$ & $68.2 \pm 8.7$ & $75.1 \pm 6.4$ & $72.4 \pm 9.1$ & $72.5 \pm 7.8$ & 0.704 \\
\hline $\mathrm{CO}$ & $1.95 \pm 0.43$ & $1.59 \pm 0.28$ & $1.57 \pm 0.57$ & $1.64 \pm 0.71$ & $1.44 \pm 0.65$ & 0.038 \\
\hline PAPsys & $27.6 \pm 4.3$ & $28.7 \pm 7.1$ & $27.7 \pm 5.6$ & $28.8 \pm 6.1$ & $29.8 \pm 7.3$ & 0.063 \\
\hline PAPdys & $6.6 \pm 2.7$ & $7.6 \pm 4.1$ & $7.1 \pm 3.2$ & $8.8 \pm 1.9$ & $8.3 \pm 3.4$ & 0.401 \\
\hline EVLW & $221.5 \pm 61.2$ & $245.3 \pm 74.7$ & $267.5 \pm 58.4$ & $247.1 \pm 73.3$ & $263.8 \pm 70.5$ & 0.077 \\
\hline
\end{tabular}

Results expressed as mean \pm SD. SD, standard deviation; HR, heart rate (bpm); ABPsys, systolic arterial blood pressure (mmHg); ABPdys, diastolic arterial blood pressure $(\mathrm{mmHg})$; CVP, central venous pressure $\left(\mathrm{cmH}_{2} \mathrm{O}\right)$; $\mathrm{CO}$, cardiac output $(\mathrm{L} / \mathrm{min})$; PAPsys, systolic pulmonary artery pressure $(\mathrm{mmHg})$; PAPdys, diastolic pulmonary artery pressure $(\mathrm{mmHg})$; EVLW, extravascular lung water $(\mathrm{mL} / \mathrm{kg})$.

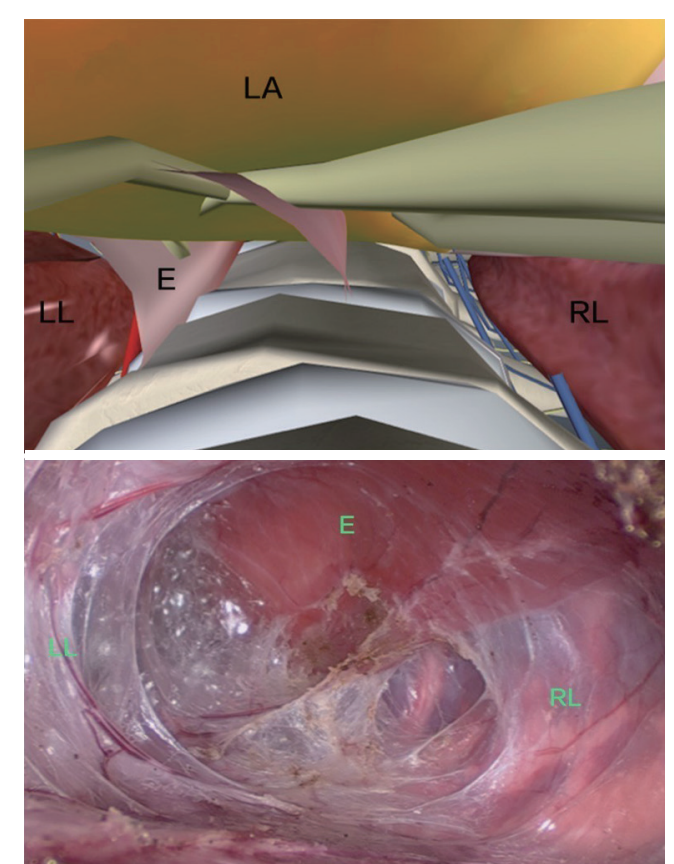

Figure 6 The digital and endoscopic anatomy of the surgical field of lower thoracic esophagus during transcervical minimally invasive esophagectomy. E, esophagus; LA, left atrium; RL, right lung; LL, left lung.

have laid an important theoretical and practical foundation for carrying out this experiment.

Higher pneumomediastinal pressure will lead to intraoperative hemodynamic instability, and potentially increase the risk of post-operative morbidities. Moreover, when pneumoperitoneum is simultaneously introduced during the abdominal stage, the insufficient tissue perfusion would further predict a series of complications $(17,18)$. However, the optimal range of pneumomediastinum pressure remain less discussed: previously, similar procedures by Parker and colleagues used $12 \mathrm{mmHg}$ artificial pneumomediastinum $\mathrm{CO}_{2}$ pressure, which did not involve the measurement of hemodynamic parameters $(9,10)$. In 2015, Tokairin and associates published the study on single-port minimally invasive esophagectomy via neck, which only adopted $6 \mathrm{mmHg}$ pneumomediastinal pressure (11).

For experimental animal swine, $4-16 \mathrm{mmHg} \mathrm{CO}_{2}$ artificial pneumomediastinum resulted in no difference in hemodynamic parameters at upper thoracic stage, to which less cardio-thoracic manipulations were performed. As a result, it is hard to have a direct hemodynamic effect from this stage. Therefore, the use of $4-16 \mathrm{mmHg}$ pressure is suitable for this stage.

At middle thoracic stage, the operation continues along the trachea to the ventral side. At $16 \mathrm{mmHg}$ pneumomediastinal pressure, the animal's CO dropped significantly, which was symbolic in artificial pneumomediastinum. Meanwhile, the exposure of surgical field under $12 \mathrm{mmHg}$ pneumomediastinal pressure is identical to $16 \mathrm{mmHg}$, without significant changes in hemodynamic parameters. Therefore, it is appropriate to choose $12 \mathrm{mmHg}$ as the highest artificial pneumomediastinum pressure at this stage. In this stage, the surgery encounters more challenges including the limited surgical field and 
Table 3 Relationship between $\mathrm{CO}_{2}$ pressure and hemodynamic parameters during lower thoracic stage

\begin{tabular}{|c|c|c|c|c|c|c|}
\hline \multirow{2}{*}{ Parameters } & \multicolumn{5}{|c|}{ Pneumomediastinal pressure } & \multirow{2}{*}{$\mathrm{P}$} \\
\hline & $0 \mathrm{mmHg}$ & $4 \mathrm{mmHg}$ & $8 \mathrm{mmHg}$ & $12 \mathrm{mmHg}$ & $16 \mathrm{mmHg}$ & \\
\hline $\mathrm{HR}$ & $81.7 \pm 4.4$ & $81.4 \pm 5.2$ & $78.3 \pm 3.6$ & $76.8 \pm 5.8$ & $75.1 \pm 4.8$ & 0.634 \\
\hline ABPsys & $116.6 \pm 9.2$ & $110.4 \pm 12.1$ & $104.7 \pm 8.9$ & $89.0 \pm 10.5$ & $82.4 \pm 11.6$ & 0.501 \\
\hline ABPdys & $71.0 \pm 9.3$ & $68.6 \pm 8.1$ & $70.7 \pm 5.8$ & $53.9 \pm 6.9$ & $66.5 \pm 7.1$ & 0.667 \\
\hline $\mathrm{CO}$ & $1.75 \pm 0.36$ & $1.75 \pm 0.43$ & $1.72 \pm 0.34$ & $1.62 \pm 0.77$ & $1.51 \pm 0.53$ & 0.022 \\
\hline PAPsys & $28.4 \pm 5.7$ & $29.3 \pm 7.1$ & $31.2 \pm 4.7$ & $28.9 \pm 4.1$ & $29.7 \pm 8.4$ & 0.287 \\
\hline PAPdys & $6.9 \pm 2.1$ & $7.4 \pm 3.3$ & $8.1 \pm 2.9$ & $8.4 \pm 5.5$ & $7.1 \pm 3.2$ & 0.752 \\
\hline EVLW & $276.1 \pm 55.8$ & $286.6 \pm 70.4$ & $269.3 \pm 64.5$ & $278.7 \pm 60.2$ & $281.2 \pm 54.6$ & 0.339 \\
\hline
\end{tabular}

Results expressed as mean \pm SD. SD, standard deviation; HR, heart rate (bpm); ABPsys, systolic arterial blood pressure (mmHg); ABPdys, diastolic arterial blood pressure $(\mathrm{mmHg})$; CVP, central venous pressure $\left(\mathrm{cmH}_{2} \mathrm{O}\right)$; $\mathrm{CO}$, cardiac output $(\mathrm{L} / \mathrm{min})$; PAPsys, systolic pulmonary artery pressure $(\mathrm{mmHg})$; PAPdys, diastolic pulmonary artery pressure $(\mathrm{mmHg})$; EVLW, extravascular lung water $(\mathrm{mL} / \mathrm{kg})$.
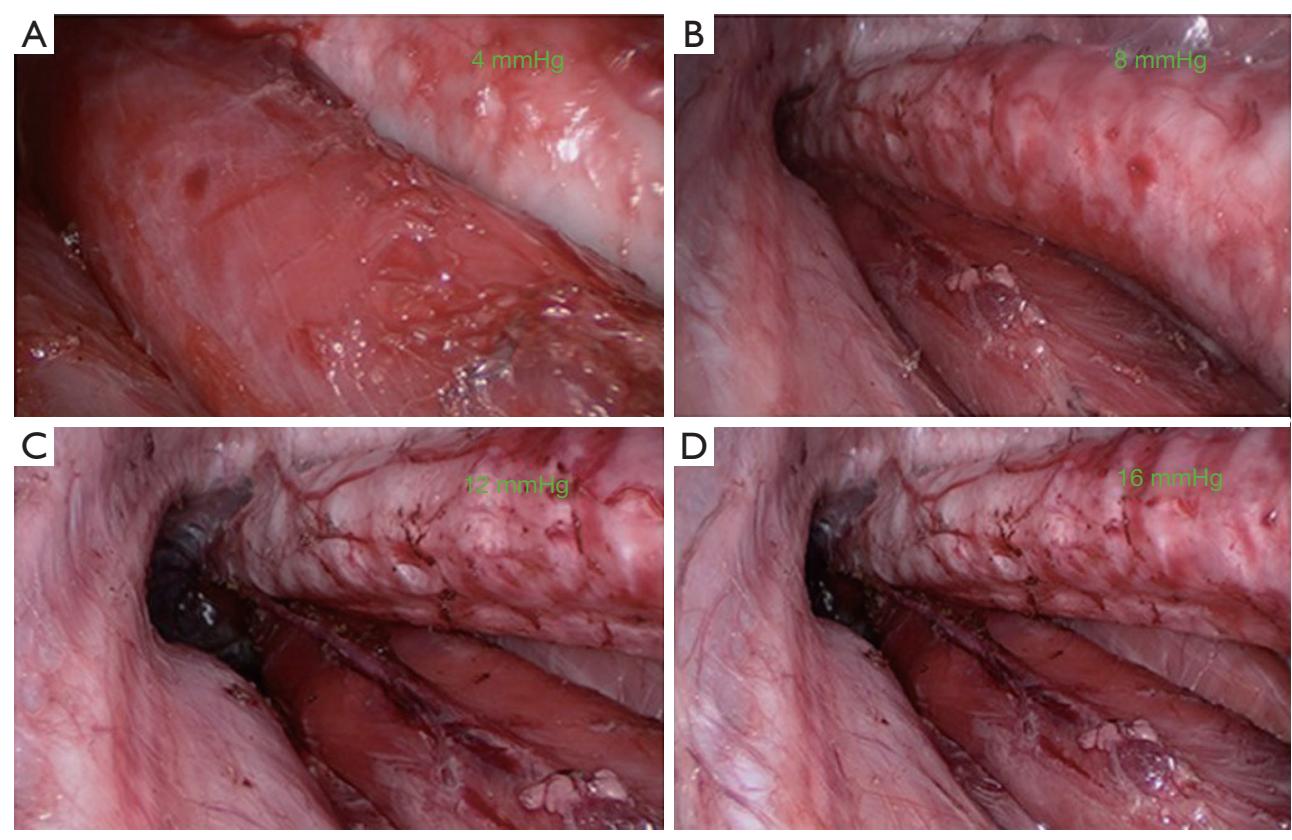

Figure 7 Comparison of surgical fields under different artificial pneumomediastinal pressures: (A) $4 \mathrm{mmHg}$; (B) $8 \mathrm{mmHg}$; (C) $12 \mathrm{mmHg}$; (D) $16 \mathrm{mmHg}$. Changes in the position of mediastinal organs of experimental animals under pneumomediastinum.

instrumental collision, which made the iatrogenic injuries easier by the energy of the ultrasonic blade (19). The thermal injury towards the trachea or bronchus is often insignificant during surgery, but it is easy to cause tracheo-esophageal fistula post-operatively.

At lower thoracic stage, the pneumomediastinum pressure over $12 \mathrm{mmHg}$ will be inappropriate. The pneumomediastinal pressure acts directly on the left atrium during the mobilization of lower thoracic esophagus, thus high pressure will result in restricted circulatory blood flow and lower perfusion thereafter. Due to the accumulation of surgical time, the impact on respiratory and circulatory function also gradually appeared at this stage. In addition, during this stage, the esophagus will gradually depart 
from the spine to the ventral direction, and towards the right side, thus increasing the risk of contralateral pleural injury. In order to shorten the period below the carina, mobilization could be performed partly during the abdominal stage. Recently, Shiozaki and associates have reported laparoscopic completion of the dissection of subcarinal lymph nodes, which proved the feasibility of transabdominal lymphadenectomy in subcarinal station (20).

As the surgery advances towards the caudal side, the maximum artificial pneumomediastinal pressure that the experimental animal can tolerate gradually decreases. It is manifested by consecutive decrease in $\mathrm{CO}$ and increase in CVP, which inspires the idea of applying these parameters to evaluate the surgery. In recent studies, scholars have proposed surgical Apgar scores (including minimum arterial pressure, the volume of blood loss etc.), and the literature suggests that surgical Apgar score is predictive to perioperative complications and mortality in thoracic surgery (21). On the other hand, these parameters would also provide information on the switch from intra-operative manipulation to post-operative complications.

In general, based on the results of transcervical minimally invasive esophagectomy on animal studies, the optimal pneumomediastinal pressure is well defined at different anatomical levels. Our pre-clinical study has certain limitations due to its animal setting under small case volumes. Further study will be required to validate these findings.

\section{Acknowledgments}

Funding: This work was supported by National Natural Science Foundation of China (81400681), China Postdoctoral Science Foundation Grant (2018M631394), and Project of Sichuan Province's Health Committee (17PJ190).

\section{Footnote}

Reporting Checklist: The authors have completed the ARRIVE reporting checklist. Available at http://dx.doi. org/10.21037/jtd-20-1905

Data Sharing Statement: Available at http://dx.doi. org/10.21037/jtd-20-1905

Conflicts of Interest: All authors have completed the ICMJE uniform disclosure form (available at http://dx.doi. org/10.21037/jtd-20-1905). The authors have no conflicts of interest to declare.

Ethical Statement: The authors are accountable for all aspects of the work in ensuring that questions related to the accuracy or integrity of any part of the work are appropriately investigated and resolved. Experiments were performed under a project license (No. 2009156) granted by ethics board of Zhongshan Hospital, in compliance with institutional guidelines for the care and use of animals.

Open Access Statement: This is an Open Access article distributed in accordance with the Creative Commons Attribution-NonCommercial-NoDerivs 4.0 International License (CC BY-NC-ND 4.0), which permits the noncommercial replication and distribution of the article with the strict proviso that no changes or edits are made and the original work is properly cited (including links to both the formal publication through the relevant DOI and the license). See: https://creativecommons.org/licenses/by-nc-nd/4.0/.

\section{References}

1. Orringer MB, Marshall B, Chang AC, et al. Two thousand transhiatal esophagectomies: changing trends, lessons learned. Ann Surg 2007;246:363-72; discussion 372-4.

2. Buess G, Becker HD. Minimally invasive surgery in tumors of the esophagus. Langenbecks Arch Chir Suppl II Verh Dtsch Ges Chir 1990:1355-60.

3. Bumm R, Hölscher AH, Feussner H, et al. Endodissection of the thoracic esophagus. Technique and clinical results in transhiatal esophagectomy. Ann Surg. 1993;218:97-104.

4. DePaula AL, Hashiba K, Ferreira EA, et al. Laparoscopic transhiatal esophagectomy with esophagogastroplasty. Surg Laparosc Endosc 1995;5:1-5.

5. Luketich JD, Alvelo-Rivera M, Buenaventura PO, et al. Minimally invasive esophagectomy: outcomes in 222 patients. Ann Surg 2003;238:486-94; discussion 494-5.

6. Bumm R, Feussner H, Bartels H, et al. Radical transhiatal esophagectomy with two-field lymphadenectomy and endodissection for distal esophageal adenocarcinoma. World J Surg 1997;21:822-31.

7. Gallego-Poveda J, Guerra NC, Carvalheiro C, et al. Use of $\mathrm{CO} 2$ in video assisted thoracic surgery and single-lumen endotracheal tube-a new less invasive approach. J Thorac Dis 2017;9:903-6.

8. Mori K, Aikou S, Yagi K, et al. Technical details of videoassisted transcervical mediastinal dissection for esophageal 
cancer and its perioperative outcome. Ann Gastroenterol Surg 2017;1:232-7.

9. Parker M, Bowers SP, Goldberg RF, et al. Transcervical videoscopic esophageal dissection during two-field minimally invasive esophagectomy: early patient experience. Surg Endosc 2011;25:3865-9.

10. Parker M, Pfluke JM, Shaddix KK, et al. Video: transcervical videoscopic esophageal dissection in minimally invasive esophagectomy. Surg Endosc 2011;25:941-2.

11. Tokairin Y, Nagai K, Fujiwara H, et al. Mediastinoscopic subaortic and tracheobronchial lymph node dissection with a new cervico-hiatal crossover approach in thiel-embalmed cadavers. Int Surg 2015;100:580-8.

12. Wang X, Li X, Cheng H, et al. Single-port inflatable mediastinoscopy combined with laparoscopic-assisted small incision surgery for radical esophagectomy is an effective and safe treatment for esophageal cancer. J Gastrointest Surg 2019;23:1533-40.

13. Chiu PWY, Ng SSM, Au SKW. Transcervical minimally invasive esophagectomy using da Vinci® SP ${ }^{\mathrm{TM}}$ Surgical System: a feasibility study in cadaveric model. Surg Endosc 2019;33:1683-6.

14. Feng MX, Wang H, Zhang Y, et al. Minimally invasive esophagectomy for esophageal squamous cell carcinoma: a case-control study of thoracoscope versus mediastinoscope assistance. Surg Endosc 2012;26:1573-8.

15. Feng M, Shen Y, Wang H, et al. Thoracolaparoscopic

Cite this article as: Chen $\mathrm{X}$, Xue S, Xu J, Zhong M, Liu X, Lin G, Shen Y, Tan L. Transcervical minimally invasive esophagectomy: hemodynamic study on an animal model. J Thorac Dis 2020;12(11):6505-6513. doi: 10.21037/jtd-20-1905 esophagectomy: is the prone position a safe alternative to the decubitus position? J Am Coll Surg 2012;214:838-44.

16. Wang H, Shen Y, Feng M, et al. Outcomes, quality of life, and survival after esophagectomy for squamous cell carcinoma: a propensity score-matched comparison of operative approaches. J Thorac Cardiovasc Surg 2015;149:1006-14; discussion 1014-5.e4.

17. Jones MG, Rae W, Lwin AA, et al. Pneumomediastinum leading to respiratory compromise as a complication of acute severe asthma. Am J Respir Crit Care Med 2013;187:e5-6.

18. Lin MC, Lee CL, Chen CY, et al. Pneumoperitoneum complicated pneumomediastinum causing cardiovascular deterioration in a low-body-weight premature infant during laparoscopic Nissen fundoplication. Acta Anaesthesiol Taiwan 2013;51:177-9.

19. Schweigert M, Dubecz A, Beron M, et al. Management of anastomotic leakage-induced tracheobronchial fistula following oesophagectomy: the role of endoscopic stent insertion. Eur J Cardiothorac Surg 2012;41:e74-80.

20. Shiozaki A, Fujiwara H, Konishi H, et al. Novel technique for dissection of subcarinal and main bronchial lymph nodes using a laparoscopic transhiatal approach for esophageal cancer. Anticancer Res 2013;33:2577-85.

21. Janowak CF, Blasberg JD, Taylor L, et al. The Surgical Apgar Score in esophagectomy. J Thorac Cardiovasc Surg 2015;150:806-12. 